\title{
Solar Dollars: A Complementary Currency that Incentivizes Renewable Energy
}

\author{
Thomas H. Greco, Jr* \\ Independent Consultant, Tucson, AZ, United States
}

Incentives are the key to addressing climate change and the various other aspects of the current multi-dimensional mega-crisis. This paper proposes the issuance of private community currency vouchers by electric utility companies based on their willingness and ability to provide their customers with energy derived from renewable sources. By monetizing the value of renewable energy in the form of a community currency Solar Dollars help to solve several critical problems at once: They incentivize a more rapid shift to renewable energy, help communities to become more resilient and self-determined, and enable the decentralization of economic and political power.

OPEN ACCESS

Edited by:

Ljubomir Jankovic, University of Hertfordshire, United Kingdom

Reviewed by:

Silvio Carta

University of Hertfordshire, United Kingdom

Donagh Horgan,

University of Strathclyde,

United Kingdom

${ }^{*}$ Correspondence:

Thomas H. Greco

thg@mindspring.com

Specialty section: This article was submitted to

Urban Science,

a section of the journal

Frontiers in Built Environment

Received: 28 September 2021 Accepted: 09 November 2021 Published: 13 December 2021

Citation:

Greco TH (2021) Solar Dollars: A Complementary Currency that Incentivizes Renewable Energy. Front. Built Environ. 7:785145 doi: 10.3389/fbuil.2021.785145
Keywords: renewable energy, complementary currency, community self-reliance, interest-free credit, vouchers, exchange, railway money

\section{INTRODUCTION}

The multi-dimensional mega-crisis confronting the world today derives primarily from the fact that the incentives that are built into the economic and financial structures of our global civilization promote behaviors that are antithetical to its solution (Greco, 2009, 2010). The compound interest that is built into the political money system forces continual expansion of debt which in turn drives perpetual and unnecessary economic growth, centralization of economic and political power, and concentration of wealth in ever fewer hands, all of which leads to social stratification, increased poverty, and despotic government. The political policies and legislation that favor expansion and agglomeration of corporations reduce competition and drive out small and medium sized enterprises. The over emphasis on private corporate profits causes large companies to disregard environmental impacts and the common good, and since their profits are dependent upon repeat sales, they have a disincentive to produce products that are durable, reparable, or recyclable, thus causing excessive waste and disposability over conservation or environmental regeneration.

There is no need to argue whether or not climate change is real and whether or not it is caused or exacerbated by human activities, it is clear that our ability to successfully address the various aspects of the crisis depends on the design and deployment of new systems and structures that incentivize different behaviors. When proper incentives are provided behaviors will change accordingly. Solar Dollar currencies are one step in that direction.

\section{BACKGROUND}

In good times and bad, local economies find themselves short of liquidity. Communities always find that, to some degree or other, there is unused business capacity alongside unmet consumer needs. 
What is usually lacking is sufficient money circulating in the community to connect these unmet needs with the unused supplies. It is a situation that derives from our banking system which is increasingly centralized and reluctant to provide credit to local businesses, especially the small and medium sized enterprises (SMEs) that are the backbone of every economy. If and when banks do provide them with credit, it is on onerous terms, including high interest rates, burdensome repayment schedules, and the demand for collateral assets to secure the loans.

The defects and instabilities inherent in our system of money and banking increasingly appear to be insoluble. In the credit expansion phase, banks create asset price bubbles based on government guarantees, subsidies, and/or the expectation of government bailouts when the loans go bad. Then, in the contraction phase, they become risk averse, choosing to invest in "safe" government and corporate securities rather than financing the legitimate needs of businesses in their communities, especially the SMEs.

At the same time, industrialization and population growth are causing other problems including despoliation of the natural environment and climate destabilization. It is clearly desirable to shift our energy production from fossil fuels to renewable sources but the incentives for doing that have not been adequate to propel this shift quickly enough to stave off severe environmental, economic, and political consequences.

Solar Dollars (SD) are intended to address at once the needs of the environment for reductions in greenhouse gas emission, the needs of local communities for more circulating payment media, and the needs of utility companies for low cost financing. ${ }^{1}$

\section{METHODS}

\section{How Solar Dollars Are Issued?}

A Solar Dollar (SD) is a credit instrument of a local electric utility company. The circulation of SD begins when a contractor or supplier accepts them directly from the utility company in payment for services rendered to it. To the extent that contractor or supplier himself can utilize the services of the utility company, the SD clearly have value for him because he can use them to pay his electric bill. For example, if the contractor has electric bills averaging $\$ 500$ per month, he could easily utilize SD amounting to at least $\$ 1,000$ in face value.

To the extent that the contractor is unable to use SD directly in operating his business, he will seek to pass them on as payment to his sub-contractors and suppliers who themselves have electric bills to pay. He will therefore seek to source the goods and services he needs from those who are willing to accept SD as payment.

${ }^{1}$ Solar Dollars represent a special kind of privately issued currency, of which there have been many historical precedents, most notably the "Railway Money" issues of the 19th and 20th centuries. Other such issues were proposed during the Great Depression of the nineteen thirties. Of particular relevance is a proposal made by Dr. Walter Zander, 1933 in 1934, the English language version of which was published by Williams and Norgate Ltd., London in 1935, under the title: "Ending the Unemployment and Trade Crisis by the introduction of purchasing certificates and the establishment of an international clearing system."
These sub-contractors in turn will undoubtedly be able to use some amount of SD directly to pay their own electric bills and will pass on the rest to other vendors that supply them. Now, since virtually everyone has a need for electricity, the local economy should be able to absorb a large amount of SD vouchers, with shopkeepers and even employees at all levels of the supply chain being willing to accept them at least as partial payment.

\section{Circulation and Value of Solar Dollars}

Of course, a particular amount of SD vouchers, between the time they are first issued into circulation and the time they are presented back to the utility as payment for electricity services, can change hands many times as others in the community use them to pay one another. There is a multiplier effect in stimulating local business because now the supply of dollars or other official currency has been augmented by this entirely local medium of exchange. Many bills that would otherwise require payment in dollars can now be paid using SD, an entirely "homegrown" payment medium the creation of which does not require any bank loans or action by the central monetary authorities. Still, SD can be a sound and dependable exchange medium because they represent a claim on a valuable service, electricity provided by the utility company.

The value of SD vouchers in the market will be determined by the law of supply and demand. If the amount issued (supply) becomes excessive in relation to the collective needs of those in the community for electricity services (demand), the SD will begin to be discounted, i.e., they will be accepted at a rate below face value. This will occur because there is no legal compulsion for anyone to accept them at face value, or to accept them at all. For example, if shopkeepers in the community perceive a superabundance of SD being offered as payment from their customers, an amount that is beyond the amount that they and their trading partners can use within a reasonable span of time, they might begin to accept them at less than face value. A one dollar SD note might be accepted at the rate of only 95 or even 90 cents. At the latter rate, an item with a cash price of $\$ 90$ would require payment in SD with a face value of 100 .

But as the market rate for SD drops, anyone who has an electric bill to pay will be more eager to acquire them since the electric company that issued them is compelled at all times to accept them at face value. Once a significant amount of SD vouchers enter circulation, it is likely that a free market for trading them will develop. Large users of electricity will be ever on the lookout to buy them whenever their price falls much below par.

However, the utility, finding that its contractors and suppliers are no longer willing to accept SD at par, will cut back on its rate of issue until supply and demand come back into balance and the discount is eliminated.

Since no one other than the issuer is compelled to accept SD or any other private currency as payment, such currencies are selfcorrecting. This feature makes them superior to political currencies that rely upon legal compulsion (legal tender) as the basis for their circulation above and beyond their acceptability for the payment of taxes. 


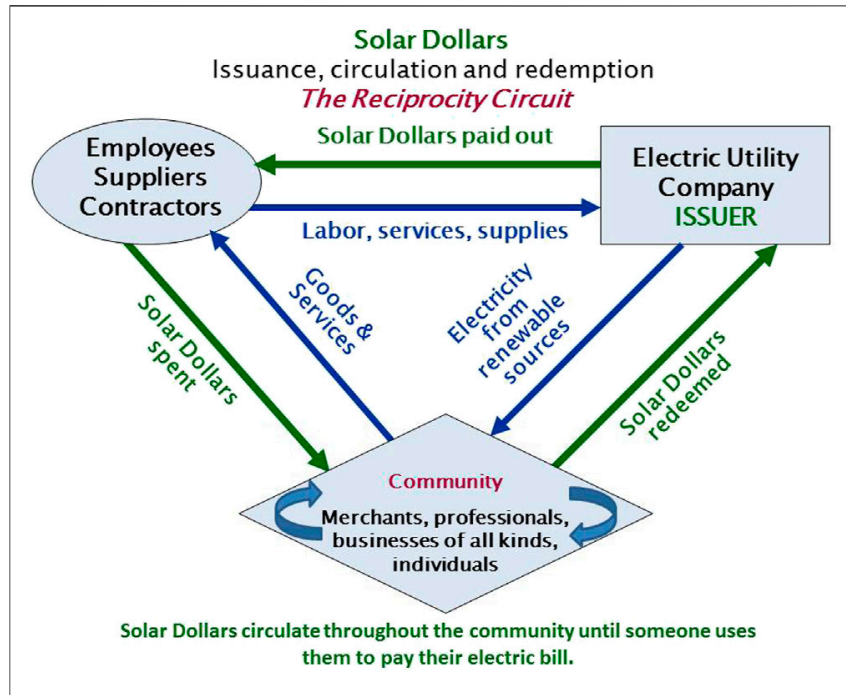

FIGURE 1 | Solar Dollars: Issuance, circulation and redemption.

\section{EXPECTED RESULTS}

\section{Benefits of Solar Dollars to the Utility Company}

The issuance of SD by the utility in the way described is analogous to the emission of a short term credit note or account payable, however SD by comparison have two advantages, first, there is no interest cost and secondly, there is no redemption in official money-the SD vouchers are redeemed only by the provision of electric services. This is especially significant during times of financial stringency and economic recession when official money may be in short supply.

As Dr. Zander pointed out more than 80 years ago with regard to a similar proposal for a railway currency (Roll and Milhaud, 1935), when the company issues a note that promises to pay cash at a later time, it "undertakes to deliver something at a fixed date which at the time of the promise it only hoped to obtain. Whether its hope will materialize, is uncertain. The undertaking to pay at maturity contains therefore a speculative element, which is particularly hazardous in times of depression. It is therefore obvious that the Railway must be extremely circumspect in making credit purchases i.e. in promising to pay at a later date with resources which have yet to be secured. But the Railway may promise something else, namely, to transport commodities and persons, that is, to fulfill its function as a Railway. There is nothing speculative about that."

Likewise, in issuing Solar Dollars, a utility company is promising to provide electricity, that is, to fulfill its function as an electric utility; there is nothing speculative about that. The utility company's only obligation is that it should accept the SD at any time at their face value, irrespective of their current market rate. It would be in no way obligated to redeem the SD in cash or in any other way.

Once the SD vouchers have been presented to the company and accepted as payment for electricity, the SD will have completed the reciprocity circuit and will be retired (Figure 1). Of course new SD vouchers can be put into circulation (or old ones recycled) so long as the amount outstanding at any point in time does not become so great as to cause the market rate to fall too low below par. Thus, there can be a continuous flow of SD through the local economy as new vouchers enter it (when the utility spends them) and old vouchers are retired (when the utility accepts them back as payment for services).

\section{DISCUSSION}

\section{How Much Solar Dollar Currency Could be Issued?}

In the general case of a private currency that is spent into circulation the amount that can be safely issued depends first of all upon the solvency or general financial condition of the issuing company, indeed, the market will be unlikely to accept the currency of a company that is on shaky ground and at risk of failing. Assuming that the company is sound financially however, its currency becomes merely another short-term credit obligation. But unlike other short-term obligations like accounts payable or notes payable, private currency vouchers can be used by the entire community as a means of payment that is supplementary to the available supply of official currency.

Lacking legal tender status, a private currency must stand on its own merits in the marketplace. The value that the community places on the currency will depend primarily upon the demand for the products or services that are its foundation. In the case of Solar Dollars, that foundation is the ability of the company to provide electricity services. A further factor in determining the amount that can be outstanding at any particular time is the extent to which people wish to use it as a medium of exchange; the greater the use of the currency as an exchange medium, the greater the amount of it that the community can absorb. The signal that needs to be monitored in making the ultimate determination of the volume of currency that can be circulated is the market rate at which the currency passes. As pointed out above, if the discount from par becomes significant, that is an indication that the amount issued is becoming excessive and needs to be throttled back.

Here it is useful to introduce three concepts "emission," "reflux," and "turnover". We are describing here a continuous process of issuance and redemption of the currency. Each occurs at a particular rate. The rate of issuance or the rate at which currency "goes out" is termed emission, and the rate of redemption or the rate at which currency "comes back" is termed reflux. Suppose the rate of issuance (emission) is 30,000 per month and the rate of redemption (reflux) averages 20,000 per month. You can see that the amount outstanding will be building up by 10,000 per month and over a period of time the market will eventually become saturated. The point at which saturation occurs will be indicated by the market in the form of the discount at which the currency passes. At that point the emission must be reduced and/or the reflux increased. Since there is little the issuer can do to control the reflux, the adjustment will typically be made by reducing the emission until the discount is eliminated. In the long run the emission must match the reflux. There is however a rule of thumb or heuristic that is based on past experience that can be used as a rough guide to estimate the maximum amount that might be outstanding at any particular 
time. It says that there should be no less than a $1 \%$ daily reflux (Greco, $2009,2010)$. In other words the amount of currency outstanding should be able to be retired in the normal course of business within a period of about 100 days or less. This period is the "turnover," the period of time in which the entire amount outstanding will be replaced with newly issued currency. Of course any currency should be put into circulation gradually and its market rate and circulation closely monitored so that adjustments can be made long before the maximum amount is reached.

In the special case of Solar Dollar currency there is an additional constraint that is intentionally built into the program. Besides the objectives of providing the local economy with a supplemental means of payment and providing the utility company with interest-free financing, the Solar Dollar program has another fundamental objective, that is to promote the shift from fossil fuel energy to renewable energy. This environmental objective is achieved by limiting the issuance of Solar Dollars to some fraction of the value of only the renewable energy that the company delivers to its customers. This feature provides the proper incentives to the company and to the prospective payees and users of the SD vouchers.

The utility company will want to deliver more energy that is generated from renewable sources because that will allow it to issue more SD which provides it with more interest-free credit. The company's suppliers and anyone else in the community who favors the shift to more renewable energy will want to accept SD in payment as a way of supporting that shift.

\section{In What Units Should Solar Dollars be Denominated?}

The Solar Dollar being a credit instrument must be denominated in some particular unit of measure. We are assuming that SD would be denominated in units of measure equivalent to the predominant currency in the area, like the United States dollar, the Euro, or pound sterling, for example. That would be the most convenient choice since the company bills its customers in those units. Thus, if you receive a bill from the utility saying you owe $\$ 100$ for electric services, you have the choice of paying with dollars from your checking or credit card account, or, if you happen to have 100 SD vouchers, you can pay with them instead.

However it is interesting to consider another possibility. Suppose the Solar Dollars were denominated in terms of some unit that is better defined than the United States dollar, something real, like electricity units? The usage of electricity is measured in kilowatt-hours (Kwh), and the company bills its customers at the rate of so many cents per Kwh to arrive at the dollar amount of each customer's bill. But rates are subject to change (with approval of the regulatory agency that has jurisdiction in that area). If SD were denominated in Kwh units, each would be good for payment of a kilowatt-hour, regardless of the going price of a Kwh at the time of payment. This would have the advantage of protecting the holder of SD from any possible increase in price. Of course, in the case of public utilities, requests for rate increases are announced well in advance of any actual increase so the market will have plenty of time to adjust its valuation of SD vouchers. But, in the general case of a private currency, denomination in real units instead of dollars becomes a more interesting option, especially in times when general price inflation is rampant and the purchasing power of the dollar is declining rapidly.

\section{In What Form Should Solar Dollars be Emitted?}

It is important to understand the distinction among these three aspects of currency circulation:

- The essence of a currency,

- Its form of manifestation, and

- Its methods of transmittal.

These are three separate things that are often mistakenly conflated in discussions about currency innovation and development.

The essence of a currency is credit. It is the issuer's i. o.u. or promise to reciprocate, i.e., to provide real value and accept his currency back as payment. SD is a credit instrument that is spent into circulation by the utility company.

A currency can manifest as a paper note, a number in a ledger (written or computerized), a smart card balance, or some other electronic format. SD might be circulated in any or all of these forms, but if paper vouchers or tokens are issued they should carry an expiration day to prevent them being hoarded and causing disruption in their circulation.

A currency can be transmitted hand to hand as in the case of paper notes or tokens, electronically within a ledger of accounts using debit cards or SMS messaging, or directly from one electronic wallet to another using perhaps near field communication technologies. This is a rapidly developing field in which convenience must be balanced against security. But since every SD unit is accounted for at all times, fraudulent or improper transactions can be refused or reversed.

\section{The Solar Dollars Model can be Applied to Other Goods and Services}

Note that this same basic currency model can be used not only to promote the shift to renewable energy but also to promote other desirable economic shifts. The fact is that the value of any product or service that is in everyday demand can be monetized in the form of a private currency. Providers of organically produced food, for example, could issue Organic Dollars or Bio Dollars by using them to pay their contractors, suppliers, and employees, in just the same way as we described for the issuance of Solar Dollars. The requirements remain the same-that they be spent into circulation by a trusted issuer that is ready, willing, and able to accept their currency back as payment, at face value, for the goods and services they sell.

\section{CONCLUSION}

To conclude, the Solar Dollar currency is one instance of a complementary currency that is spent into circulation by a trusted seller of goods or services that are in everyday 
demand, and who is ready, willing, and able to redeem and their currency at face value as payment. Such currencies are able to provide numerous benefits not only to the issuing company but also to the community and the environment.

\section{Financial and Economic Benefits}

- Vouchers, such as SD, that are spent into circulation provide an interest-free source of working capital to the issuing company. As such, they provide significant interest cost savings over bank loans.

- Vouchers spent into circulation by a trusted entity such as a local utility company provide the local community with home-grown liquidity, i.e., a supplemental means of payment that is independent of the monetary policies of banks and central government, providing the community with a greater measure of self-determination and making the local economy more resilient.

- Vouchers, such as SD, that are spent into circulation by a trusted issuer can change hands many times between their issuance and their redemption, thus stimulating local business.

- Home-grown liquidity based on the production of real goods and services provides sound exchange media that stays local and encourages local economic development. Locally issued currency vouchers, by their nature, stimulate local production and prosperity because they tend to stay within the community, and even if they do range more widely, must ultimately come back home to be redeemed by the issuer when accepted as payment for utility bills.

\section{Environmental Benefits}

- Anyone who is concerned about problems like global warming, pollution, depletion of fossil fuels, the ill effects of resource extraction like fracking and offshore drilling, will want to encourage a shift to renewable energy sources. Accepting the company's own solar energy vouchers as payment will provide that encouragement and help move the company toward the goal of providing more of its energy from renewable sources. The more renewable energy the company produces or distributes, the more Solar Dollars it will be allowed to issue, providing it with a greater amount of interest-free credit.

\section{REFERENCES}

Greco, T. H. (2009). The End of Money and the Future of Civilization. White River Junction, VTEdinburgh: Chelsea Green PublishersFloris.

Roll, E., and Milhaud, E. (1935). Ending the Unemployment and Trade Crisis. Econ. J. 45, 570. doi:10.2307/2225005

Zander, W. (1933). Railway Money and Unemployment Annals of Public and Cooperative Economics. Ann. Public Coop. Econ., 9(3), 355-368. doi:10.1111/j.1467-8292.1933.tb01415.x

Conflict of Interest: The author declares that the research was conducted in the absence of any commercial or financial relationships that could be construed as a potential conflict of interest.

\section{Public Relations, Publicity, and Image}

- There has been for some time a great and growing amount of media interest in stories about community currencies, local selfhelp initiatives, green energy, and alternative finance. This innovative project can provide a tremendous image boost to the utility company, the municipality, and the state, and establish the region as a hub of creativity and innovation. As the significant benefits of the project become apparent, all the involved entities will gain in prestige, and other communities will follow its lead.

\section{Educational Benefits}

- A private local currency that is spent into circulation by some trusted issuer like an electric utility is an important step in promulgating new memes and weaning the public away from their illusions about political currencies, like the United States dollar, as the only way to pay bills or settle accounts.

\section{DATA AVAILABILITY STATEMENT}

The original contributions presented in the study are included in the article/Supplementary Material, further inquiries can be directed to the corresponding author.

\section{AUTHOR CONTRIBUTIONS}

TG, the sole author of this article, has been actively researching and writing in the field of monetary economics for more than 40 years. $\mathrm{He}$ has recognized the flaws and dysfunctions that are inherent in the present systems of money and banking and their detrimental impact on economies, politics and the environment, and has proposed numerous solutions for reinventing the ways in which the functions of exchange, saving, and investment are carried out.

\section{ACKNOWLEDGMENTS}

A predecessor to this article was published on the author's website at https://beyondmoney.net/2016/08/26/solar-dollars-a-privatecurrency-with-multiple-benefits/.

Publisher's Note: All claims expressed in this article are solely those of the authors and do not necessarily represent those of their affiliated organizations, or those of the publisher, the editors, and the reviewers. Any product that may be evaluated in this article, or claim that may be made by its manufacturer, is not guaranteed or endorsed by the publisher.

Copyright (C) 2021 Greco. This is an open-access article distributed under the terms of the Creative Commons Attribution License (CC BY). The use, distribution or reproduction in other forums is permitted, provided the original author(s) and the copyright owner(s) are credited and that the original publication in this journal is cited, in accordance with accepted academic practice. No use, distribution or reproduction is permitted which does not comply with these terms. 